\title{
POR UMA GRADUAÇÃO EM HISTÓRIA CRÍTICA E PLURALISTA: REFLEXÕES SOBRE O CURSO DE HISTÓRIA DA UNICAMP
}

\author{
Pedro Paulo A. Funaril ${ }^{1}$
}

Resumo: O artigo trata do currículo de graduação em História na UNICAMP e em outras universidades brasileiras. $O$ estudo universitário deve visar a produção de conhecimento, antes que sua reprodução e, assim, a estrutura de curso deve, também, ter como objetivo o desenvolvimento do pensamento crítico. O artigo, então, trata do currículo de graduação na UNICAMP.

Palavras-chave: currículo de graduação em História, UNICAMP, pensamento crítico.

No momento em que se discute, em todo o Brasil, as graduações, em geral, e os cursos de História, em particular, refletir sobre o curso de Graduação História da UNICAMP revestese de particular relevância ${ }^{2}$. Proponho-me a fazê-lo a partir de uma posição muito específica, tendo sido coordenador do curso em 1993-4 e, novamente, no período 1997-8. Tendo sido aluno da Universidade de São Paulo e docente do curso de Graduação em História da UNESP (Assis), posso avaliar a diversidade de situações em cada uma das três universidades paulistas ${ }^{3}$. Ademais, há já muitos anos, tenho atuado com os formados em História, seja em sua atuação como professores de História, seja

\footnotetext{
1 Livre-Docente, Departamento de História, IFCH, UNICAMP, C. Postal 6110, Campinas, 13081-970, SP, fax 551928933 27, pedrofunari@sti.com.br.

${ }^{2}$ Este artigo representa, na substância, o paperapresentado em Seminário sobre a Graduação em História, na UNICAMP, organizado pelos coordenadores Pedro Paulo A. Funari e Margareth Rago, em 14 de outubro de 1998.

${ }^{3}$ Cf. P.P. A Funari, Aula teória e seminário, Aventuras na Sala de Aula, 1, 1987, pp. 21-22; P.P.A Funari, Pós-Graduação: Encruzilhadas atuais, Campinas, IFCH, Primeira Versão número 67, 1997.
} 
como pós-graduandos e pesquisadores ${ }^{4}$. Em todos esses casos, tenho notado o grande interesse intelectual dos estudantes de História, sua argúcia e busca de uma inserção crítica no mundo do trabalho ${ }^{5}$. Esta constatação é fundamental para que se possa discutir o ensino de graduação em História, pois o primeiro objetivo dos alunos consiste em tornarem-se profissionais capazes de alterar o status quo, de atuarem para a transformação social ${ }^{6}$.

A Educação, em geral, não pode confundir-se com adestramento, com aquilo que os alemães tão bem designam como Unterrichtung, "submissão", reprodução, mas deve ser, verdadeiramente, um crescimento interno, resultado da produção de conhecimento, Erziehung e Bildung, "exteriorização" de capacidade de refletir e atuar, "formação" para a autonomia de pensamento e ação no mundo ${ }^{7}$. Neste contexto, um curso de História não pode visar o adestramento de reprodutores de fatos e datas, menos ainda, de cartilhas historiográficas da moda. Reproduzir autores na crista da onda, tendência natural em países periféricos como o nosso, acaba por produzir reflexões datadas, pouco críticas e, sem dúvida, servis a modelos e esquemas. Um professor e/ou pesquisador que lecione e escreva a partir de um autor da moda, como foi, por exemplo, Louis Althusser, há três décadas, parece-nos, hoje, limitado, mas o mesmo se passa, na atualidade, com os best sellers atuais. Em qualquer caso, mais do que desatualizados, quando seguimos cartilhas estamos reproduzindo, mais do que criando. Cabe, ao contrário, uma prática emancipadora que possa tornar autônomos os estudiosos da História ${ }^{8}$.

\footnotetext{
${ }^{4}$ Sobre isto, com bibliografia citada, veja-se P.P.A Funari, La educación vocacional y la enseñanza de la Historia en Brasil, Revista Formación Docente Continua, Mendoza, Argentina, 2,2, 1996, pp. 88-96; P.P.A Funari \& Júlia Falivene Alves, O ensino de História no Segundo Grau: uma experiência, Campinas, IFCH, Primeira Versão número 58, 1996.

${ }^{5}$ Cf. P.P.A Funari, Ensino de História, Modernidade e Cidadania, Bolando Aula de História, 7, setembro de 1998, pp. 12-13.

${ }^{6}$ Cf. P.P.A Funari, Cidadania e compadrio: relações de poder e atividade acadêmica em questão, in Cláudio DeNipoti \& Gilmar Arruda (orgs), Cultura e Cidadania, Coletânea, volume 1, ANPUH-PR, Londrina, 1996, pp. 11-23.

${ }^{7}$ Cf. P.P.A Funari, Universidade, erudição e cidadania, Jornal da Adunicamp, maio de 1996, p. 11.

${ }^{8}$ Cf. P.P.A Funari, O ensino de História na Escola Técnica: teoria e prática, Revista Brasileira de Estudos Pedagógicos, 179/180/181, 1996, pp. 118-131.
} 
A produção de conhecimento serve tanto para o futuro professor do ensino fundamental e médio, como para o pesquisador $^{9}$. Neste sentido, cabe atentar para as Diretrizes Curriculares Nacionais do Ministério da Educação e sua ênfase no ensino da História a partir da realidade dos educandos, bem como seu abandono formal de conteúdos obrigatórios. Tradicionalmente, os livros didáticos de História tentaram abarcar toda a História, cabendo ao estudante repetir, nos exames e provas, seja as principais datas e acontecimentos, seja, nas últimas décadas, os principais esquemas interpretativos propostos nos livros. História, assim como as outras disciplinas, apareciam como práticas "decorebas" de pouco interesse e uso prático. Ora, as novas diretrizes afastam-se dessa concepção bancária de Educação, para usar uma expressão cara a Paulo Freire, buscando que o educando possa refletir sobre o mundo, a partir de sua realidade quotidiana ${ }^{10}$. Aquilo que os alemães chamam de Alltagsgeschichte ${ }^{11}$, ou História de todo o dia, surge, pois, como expressão de uma maneira menos preocupada com o conteúdo específico a ser estudado, como com a forma de estudo: busca-se a reflexão crítica, que estará a capacitar o educando, em qualquer faixa etária, a interagir com o mundo social.

Os cursos de formação universitária, neste contexto, não contam mais com as disciplinas obrigatórias explicitadas e, ao contrário, podem formular propostas curriculares que melhor explorem as potencialidades de seu corpo docente e formem profissionais de perfis específicos. Enfatiza-se, nos documentos oficiais do Ministério da Educação, que as disciplinas obrigatórias devem constituir apenas um núcleo central de formação comum para cada curso, complementada por disciplinas eletivas que se

\footnotetext{
${ }^{9}$ Cf. P.P.A Funari, Rescuing ordinary people's culture: museums, material culture and education in Brazil, in Peter Stone \& Brian L. Molineaux (ed.), The Presented Past, Heritage, musems and education, Londres, Routledge, 1994, pp. 120-136.

${ }^{10}$ Consulte-se, com referências, P.P.A Funari, Education through archaeology in Brazil: a bumpy but exciting road, Ciência e Cultura, Journal of the Brazilian Association for the Advancement of Science, 43, 1, 1991, pp 15-16.

${ }^{11}$ Cf. A Lüdtke, Alltagsgeschichte: zur Rekonstruktion historischer Erfahrungen und Lebensweise, Frankfurt, Campus Verlag, 1989; sobre o conceito, consulte-se P.P.A Funari, Archaeology, History and Historical Archaeology in South America, International Journal of Historical Archaeology, 1, 3, 1997, pp. 189-206.
}

Hist. Ensino, Londrina, v. 5, p. 127-135, out. 1999 
agrupam em temas diversos. Com isso, reconhece-se que os formandos de diferentes instituições deverão ter, necessariamente, formações diversas. Esta flexibilização curricular introduz, também, a possibilidade de especializações já no decorrer do curso de Graduação. Estas diretrizes, se aplicadas ao curso de História, implica em reconhecer a multiplicidade de caminhos a serem trilhados pelas graduações, Brasil afora, pois o que se privilegia é a especificidade e o projeto pedagógico de cada curso. Parece-me um passo ousado, se considerarmos a precariedade de muitos cursos de História, com docentes sem titulação e pouco afeitos à formulação de propostas pedagógicas e historiográficas que ultrapassem a mímese dos grandes centros. No entanto, não há que esquecer que a Lei de Diretrizes e Bases da Educação Nacional também veio a explicitar a meta de tornar os professores universitários crescentemente mais titulados, o que poderia alterar esse quadro de forma a permitir que mesmo cursos menos aquinhoados pudessem desenvolver propostas autônomas.

Neste contexto, o curso de Graduação em História da UNICAMP apresenta-se de forma particularmente apta a produzir profissionais autônomos, professores e pesquisadores. Mencione-se, en passant, a História do curso, para que se possa entender sua vocação pluralista e emancipadora. $O$ curso de História da UNICAMP surge como alternativa ao modelo de curso de massa que se generalizava no Brasil, no período militar. Poucos docentes, poucos alunos, ligação estreita entre Graduação e Pós-Graduação, linhas de pesquisa, estas algumas das características que estiveram na origem do Curso de História da UNICAMP. O curso, inserido em um Universidade que não fora criada para competir em quantidade com a Universidade de São Paulo, nunca teve como meta um curso enciclopédico, mas, ao contrário, procurou fornecer quadros instituicionais e curriculares que permitissem o florescimento de linhas de investigação temáticas, antes que cronológicas. Havia, aí, um salutar distanciamento da divisão em "setores" cronológicos da História, favorecendo o estreitamento de relações entre docentes por linhas de pesquisa e por preocupações metodológicas. Esta 
organização evitou nefastos problemas ubíquos nos "setores" cronológicos, como a rivalidade entre docentes da área, as hierarquias pouco científicas no interior dos setores, entre outros $^{12}$.

Nos últimos anos, o curso de Graduação em História da UNICAMP tem tido, crescentemente, especialistas que ministram as disciplinas obrigatórias e tópicas, assim como as disciplinas eletivas têm podido satisfazer a interesses específicos, formando profissionais de variada formação. As novas diretrizes do Ministério da Educação permitem oficializar essa pluralidade, já existente, por exemplo, no caso das disciplinas tópicas sobre História da Arte, mas que poderiam abranger também outras linhas de investigação, bastando, para tanto, que se apresentem uma série de disciplinas, mais ou menos articuladas, para abranger um campo profissional específico, como poderia ser o gerenciamento do patrimônio. $\mathrm{Na}$ verdade, o grande atout do Curso de História da UNICAMP consiste nas condições excepcionais de alunos, professores e instituicionais. Assim, os alunos passam por uma seleção não apenas muito concorrida, como, destaque-se, o exame vestibular já qualifica não a reprodução de dados, mas a reflexão, o que significa alunos mais críticos. Os professores, por sua parte, possuem titulação, produzem muito e de forma regular, com uma repercussão nacional e/ou internacional que, considerando-se o número de docentes, em relação a outros cursos, não encontra paralelo no cenário nacional. $\mathrm{O}$ impacto historiográfico de vinte e pouco estudiosos do Departamento de História da UNICAMP comparase, se não ultrapassa, dependendo de cada área de pesquisa, aos de departamentos muitíssimo mais numerosos.

Por fim, mas não menos importante, destaque-se as condições institucionais em que alunos e professores atuam. A percentagem de bolsistas graduandos do Curso de História, considerando-se as bolsas SAE, FAEP, CNPq/PIBIC e FAPESP, é incomparavelmente mais alta do que em outros cursos de História. Isto permite que os alunos adquiram uma formação muito

${ }^{12}$ Cf. P.P.A Funari, Poder, Posição, Imposição no ensino de História Antiga: da passividade forçada à produção de conhecimento, Revista Brasileira de História, 15, 1988, pp. 257 264. 
mais aprofundada, tanto para a pesquisa stricto sensu, como para o ensino, pois as bolsas de Iniciação Científica direcionamse, também, para essa área. Os docentes, em dedicação exclusiva à docência e pesquisa, muitos bolsistas pesquisadores, dedicam-se ao curso de Graduação não apenas com sua presença física em sala de aula como, o que não ocorre, com a mesma intensidade, alhures, na orientação, seja de bolsistas de Graduação, seja dos alunos em geral. O currículo permite que os alunos tenham uma formação genérica ampla, com as disciplinas obrigatórias compondo cerca de metade dos créditos, complementadas com disciplinas tópicas nas quais se pode explorar, em profundidade, temas geradores. A Universidade Estadual de Campinas tem, ainda, promovido os cursos de Graduação por meio da institucionalização das comissões de Graduação, composta, no caso do Curso de História, pelo Coordenador e Coordenador Associado de Graduação, dois outros docentes do Departamento, um docente da Licenciatura em História e um representante discente. Este quadro permite que haja quadros e contextos de discussão permanente sobre a Graudação. Regularmente, ocorrem Seminários sobre a Graduação, como o mais recente, em 13 de agosto de 1998.

$\mathrm{O}$ acervo bibliográfico disponível nas Bibliotecas da UNICAMP, com particular destaque para revistas nacionais e internacionais, constitui um patrimônio também destacável. Os Arquivos documentais, como o Arquivo Edgar Leunroth, o Centro de Memória, o SIARQ e os arquivos pessoais de intelectuais como Sérgio Buarque de Hollanda e Paulo Duarte permitem que os graduandos tenham contato direto com documentação primária de particular relevância. Os Centros e Núcleos de Pesquisa, igualmente, oferecem oportunidades de atividades acadêmicas a inúmeros graduandos, fornecendo, ainda, um contexto de atuação e reflexão interdisciplinar pouco comum na Academia, ao juntar graduandos de variados cursos da Universidade. Seminários, palestras e colóquios envolvem, de forma direta, graduandos, até mesmo com a apresentação de comunicações dos próprios estudantes. As experiências de alunos de Graduação e de Pós-Graduação que têm atuado no 
ensino de Graduação, como auxiliares didáticos e docentes no Programa de Estágio de Capacitação Docente (PECD), apresentam resultados muito profícuos e constituem uma fértil interação entre graduandos e graduados. Há, ainda, séries didáticas de publicações do IFCH, como é o caso dos "Textos Didáticos" e "Primeira Versão", além da coleção de livros-textos da Editora da Universidade Estadual de Campinas, com muitos títulos de interesse direto dos graduandos em História, produzidos por docentes da própria UNICAMP e facilmente acessíveis aos estudantes. Os estudantes têm organizado Seminários de Pesquisa, nos últimos anos, com a apresentação de investigações de Graduação e Pós e, há já alguns anos, por iniciativa autogerida, os graduandos têm feito balanços, no meio de cada semestre letivo, a respeito do andamento de cada disciplina, ambas atividades inovadoras e muito favoráveis à reflexão crítica sobre o Curso de História.

As novas Diretrizes do Ministério da Educação implicam, portanto, em atitudes que, em muitos aspectos, já se encontram na praxe do curso de História da UNICAMP, em especial sua ênfase na formação pluralista de cidadãos críticos. Ademais, abrem a possibilidade de modificações que venham a aprofundar os aspectos positivos e minimizar os problemas hoje existentes. Atualmente, o Curso de História da UNICAMP é tempo integral, ocupando os períodos matutino e vespertino, ainda que a carga horária pudesse ser concentrada em um único período, o que permitiria aos alunos utilizar-se de seu tempo mais racionalmente. Ainda quanto ao horário, as disciplinas não possuem, atualmente, horário fixo, o que dificulta, ao aluno que não segue e/ou não obtém o nota mínima em uma disciplina, terminar o curso no prazo regular, pois estará sempre sujeito a conflitos de horário insuperáveis. Assim, fixar o horário das disciplinas, em um único período, seria de grande benefício para os alunos, além de facilitar a possível criação de um Curso noturno de História, aspiração antiga de professores, alunos e da sociedade em geral, pois facilitaria sua efetivação, sem grandes transtornos para os docentes.

Outro aspecto importante das Diretrizes Curriculares 
refere-se à superação das barreiras disciplinares formais. A História tem, de forma cada vez mais intensa, mantido estreitas relações com outras ciências humanas, como as Ciências Sociais, a Filosofia, a Lingüística e as Letras, para ficar nos casos mais diretos. Esta ligação epistemológica, tão presente na Historiografia contemporânea, não tem encontrado o devido correlato na flexibilidade curricular. De fato, no momento em que a História recorre às outras ciências para formular seu próprio discurso, impõe-se um conhecimento de primeira mão, por parte dos graduandos em História, dessas áreas e ciências. Neste sentido, seria de grande benefício para os graduandos em História se pudessem seguir mais disciplinas, em particular no próprio Instituto de Filosofia e Ciências Humanas, mas também em outros Institutos, o que implicaria em permitir uma maior flexibilixação no número de créditos exteriores ao curso de História. Na prática, muitos graduandos já têm seguido disciplinas importantes para sua formação, como é o caso, em especial, de línguas, conhecimento instrumental básico para o estudo da História, mas, mesmo nestes casos, as dificuldades práticas são muitas, a começar por incompatibilidades de horário, que acabam por postergar a obtenção do título, por parte do graduando.

Um último aspecto merece menção: a inserção profissional dos formados em História da UNICAMP. Embora não se possa resumir um curso superior ao mercado de trabalho, pois que o que se busca é a formação de cidadãos, aptos a atuar no mundo de forma ampla e criativa, não se pode deixar de mencionar os caminhos trilhados pelos formados. Uma parte dos graduados dirige-se ao magistério básico e médio, destacando-se como professores que estimulam a reflexão. Outro contingente voltase à produção de material didático, enquanto muitos seguem 0 caminho da pesquisa, dos arquivos, museus e, principalmente, a carreira acadêmica. $O$ truísmo de que formandos da UNICAMP destacam-se no mercado de trabalho não deve ser mais importante do que o fato que os oriundos do curso de História da UNICAMP, via de regra, atuam de forma crítica, em qualquer das áreas. O pluralismo em sua formação significa que trilharão múltiplos caminhos, às vezes muito distantes uns dos outros, 
seja nos campos de trabalho, seja em suas posturas ideológicas. Contudo, o germe da conscientia, da construção comum do conhecimento, encontra-se em suas trajetórias de vida. A busca de uma cidadania crítica, atenta às demandas sociais, sempre se encontra no horizonte dos graduandos de História da UNICAMP. Pluralismo e crítica, duas faces de uma formação que se volta para uma práxis social criativa.

\section{Agradecimentos}

Agradeço aos colegas do Departamento de História, com os quais, particulamente como Coordenador do Curso, tenho trocado idéias sobre a Graduação, nestes últimos anos. Sou muito grato, em particular, à profa. Eliane Moura da Silva e à minha esposa, Raquel, que me deram sugestões pontuais e aos alunos, com os quais tenho, sempre, dialogado e com os quais tenho muito aprendido. A responsabilidade pelas idéias, naturalmente, restringe-se ao autor.

Abstract: The paper deals with the undergraduate history syllabus at the Campinas State University and in other Brazilian universities. University study must aim at producing knowledge, rather than reproducing it and so the course framework must also aim at fostering critical thinking. The paper then deals with the undergraduate syllabus at UNICAMP.

Key-words: undergraduate history syllabus, UNICAMP, critical thinking. 